\title{
MULHERES E MARISCAGEM: INVENÇÕES DE SI NO (IN) MUNDO MANGUE
}

\author{
WOMEN AND SHELLFISH PICKING: INVENTIONS OF THEMSELVES IN THE (UN)CLEAN) \\ MANGROVE FOREST
}

\author{
MUJERES Y COLECTA DE MARISCOS: INVENCIONES DE SÍ MISMAS EN EL (IN)MUNDO \\ MANGLE
}

\author{
Michele de Freitas Faria de Vasconcelos ${ }^{*}$ \\ Yasmin Adriane Mendonça da Rocha* \\ Sandra Raquel Santos de Oliveira** \\ Vitória Gois da Cunha ${ }^{* * * *}$ \\ Mercedes Solá Pérez \\ Elienaide Cardoso das Flores ${ }^{* * * * *}$ \\ Lucy Mirtha Ketterer Romero ${ }^{* * * x+* * *}$ \\ Sirley Ferreira dos Santos \\ Ticiane Pereira dos Santos Vieira ${ }^{* * * * * * * *}$
}

\footnotetext{
"Professora no Departamento de Psicologia e no Programa de Pós-Graduação em Psicologia da Universidade Federal de Sergipe (UFS), coordenadora acadêmica do Projeto de Fortalecimento Sociopolítico das Marisqueiras de Sergipe, vinculado ao Programa de Educação Ambiental com Comunidades Costeiras (política de mitigação dos impactos da indústria do petróleo). E-mail: michelevasconcelos@hotmail.com.

${ }^{* *}$ Graduanda em Psicologia pela UFS, foi bolsista do Projeto de Fortalecimento Sociopolítico das Marisqueiras de Sergipe, vinculado ao Programa de Educação Ambiental com Comunidades Costeiras. E-mail: yasminrocha23@hotmail.com.

"** Professora no Departamento de Psicologia da UFS, vinculada ao Grupo de Estudos e Pesquisas sobre Exclusão, Cidadania e Direitos Humanos (Gepec), coordenadora do Projeto de Implementação do Observatório Popular de Violências, pela vida de mulheres de povos e comunidades tradicionais de Sergipe. E-mail: sraquel.oliveira31@gmail.com.

${ }^{* * * *}$ Graduanda em Psicologia pela UFS, foi bolsista do Projeto de Fortalecimento Sociopolítico das Marisqueiras de Sergipe, vinculado ao Programa de Educação Ambiental com Comunidades Costeiras. E-mail: vitoriagois0@gmail.com.

***** Pós-doutoranda em Geografia pela UFS, no contexto do Programa de Educação Ambiental com Comunidades Costeiras, doutora em Geografia pela UFPE, mestra e graduada em Geografia pela UFPR. E-mail: mercedesssolap@gmail.com.

${ }^{* *+*+*}$ Graduada em Pedagogia, analista do Projeto de Fortalecimento Sociopolítico das Marisqueiras de Sergipe/PEAC/UFS, marisqueira, militante do Movimento Sem-Terra. E-mail: floreselienaide07@gmail.com.

*x+m*x Pós-doutora em Geografia pela UFS, no contexto do PEAC, professora da Universidade de La Frontera, de Temuco, Chile; compõe o Observatório de Regional Equidade em Saúde segundo Gênero e Povo Mapuche da Universidade de La Frontera.

${ }^{* * * * * * * *}$ Graduada em Gestão de Tecnologia da Informação pela Universidade Tiradentes, graduanda em Geografia pela UFS, analista do Projeto de Fortalecimento Sociopolítico das Marisqueiras de Sergipe/PEAC/UFS, membro do Conselho Estadual de Direitos das Mulheres. E-mail: sirleygti@gmail.com.

${ }^{* * * * * * * *}$ Mestra e graduada em Serviço Social pela UFS, foi analista do Projeto de Fortalecimento Sociopolítico das Marisqueiras de Sergipe/PEAC/UFS. E-mail: ticianeservicosocial@gmail.com.
} 


\section{RESUMO}

$\mathrm{O}$ artigo decorre de uma pesquisa articulada ao projeto de extensão Fortalecimento Sociopolítico das Marisqueiras de Sergipe, parte do Programa de Educação Ambiental com Comunidades Costeiras. A pesquisa faz-se processo de habitação coletiva em defesa de territórios de vida tradicionais e da vida das mulheres marisqueiras, que veem seus territórios existenciais cotidianamente ameaçados por empreendimentos do grande capital. Inspiradas na etnografia e na cartografia, miramos nos processos de invenção da vida cotidiana das mulheres no mundo mangue. A perspectiva é pesquisar com marisqueiras, conhecer seus modos de vida e formas de resistência, que se tecem num território híbrido entre cidade, campo e mangue. Acompanhamos a construção do movimento social Mulheres Marisqueiras de Sergipe e, com ele, de redes de cuidado e ajuda mútua, invençōes de si e de mundos correlatos, ampliando em ato sentidos para a categoria mulher e para o trabalho artesanal.

Palavras-chave: Marisqueiras. Cotidiano. Território. Resistência.

\section{ABSTRACT}

The present study is based on a research linked to the extension program project of Sociopolitical Empowerment of Shellfish Picker Women in the state of Sergipe, a stage of the Environmental Education Program for Coastal Communities. The project aims to empower the Movement of Shellfish Picker Women from Sergipe. The research is a process of collective habitation in defense of traditional living territories and the shellfish pickers's lives, who see, daily, their existential territories threatened by large capital enterprises. Inspired by ethnography and cartography, we focused on the processes of invention of women's daily life in the mangrove forest. The perspective is to research about shellfish picker women, learn about their lifestyle and ways of resistance, which are woven in a hybrid territory involving city, countryside and mangrove forest. We followed the construction of the social movement and, added to it, networks of care and mutual help, inventions of themselves and related worlds, broadening the meanings of the woman category and the handicraft work.

Keywords: Shellfish picker women. Daily. Territory. Resistance.

\section{RESUMEN}

El trabajo resulta de una investigación articulada al proyecto de extensión "Fortalecimiento sociopolítico de las colectoras de mariscos de Sergipe, parte del Programa de Educación Ambiental con Comunidades Costeras". El objetivo del proyecto es fortalecer el Movimiento de las Colectoras de Mariscos de Sergipe. La investigación se hace proceso de habitación colectiva en defensa de territorios de vida tradicionales y de la vida de las mujeres 
marisqueras que ven sus territorios existenciales cotidianamente amenazados por emprendimientos del gran capital. Inspiradas en la etnografía y en la cartografía miramos los procesos de invención de la vida cotidiana de las mujeres en el mundo mangle. Acompañamos la construcción del movimiento social y, con él, de redes de cuidado y ayuda mutua, invenciones de sí mismas y de mundos correlatos, ampliando sentidos para la categoría mujer y para el trabajo artesanal.

Palabras clave: Colectoras de mariscos (marisqueras). Cotidiano. Territorio. Resistencia.

\section{SOBRE UM MODO DE PESQUISAR COM, (N)A LAMA}

Dentro do mar tem rio.

Dentro de mim tem o quê?

Vento, raio, trovão.

As águas do meu querer. (Bethânia, 2006)

$\mathrm{D}$ entro do mar tem rio, tem movimento, tem vida. $\mathrm{O}$ encontro das águas doces do rio com as águas salgadas do mar faz nascer o ecossistema rico em partículas orgânicas que conhecemos por manguezal, uma vegetação que, numa primeira vista, pode não seduzir, com galhos fechados e cortantes, mas que, conforme nos misturamos a ela, que caminhamos por entre os galhos e nos permitimos afundar na lama, revela, com timidez, as múltiplas formas de vida que ali surgem, saltam, correm, multiplicam-se, escondem-se. É no encontro involuntário e inevitável das águas que a vida do mangue surge, pulsa, fazendo dele o berço de toda a vida marinha.

Tão fecundo quanto o encontro das águas foram os que tiveram como frutos desta pesquisa. Pelo projeto de uma política pública, ${ }^{1}$ pudemos adentrar territórios ribeirinhos do Estado de Sergipe, mas mais que isso, foi possível habitar territórios existenciais, carregados de sentidos que dizem de modos singulares de vida (Alvarez \& Passos, 2009), bem como ser habitadas por eles. Foi possível, ou inevitável, agenciar-se com um grupo de mulheres marisqueiras de diversas regiōes sergipanas, participantes do Movimento de Mulheres Marisqueiras, cuja assessoria e fortalecimento é o objetivo principal do projeto de que fazemos parte. Mulheres do mangue, marisqueiras, corpos invisibilizados e destituídos

\footnotetext{
${ }^{1}$ O Programa de Educação Ambiental com Comunidades Costeiras (PEAC) diz respeito a uma medida condicionante de licença ambiental exigida pelo Ibama. O projeto tem como empreendedor a Petrobrás, é executado pela Universidade Federal de Sergipe e desenvolve ações na perspectiva da Educação Ambiental Crítica, buscando o fortalecimento sociopolítico dos atores sociais diretamente afetados pela exploração de petróleo e gás.
} 
de legitimidade social. ${ }^{2}$ Cabe destacar que essa invisibilidade ou infâmia, como apontaria Foucault (2006), não é inerente aos modos de vida dessas mulheres, mas efeito de relações de poder específicas que hierarquizam corpos, produzindo vidas relegadas ao fundo de uma espécie de baú de coisas esquecidas, ganhando visibilidade apenas num lampejo de embate com essas mesmas relaçóes de poder, aparecendo nos registros dos documentos institucionais produzidos para gerir/ conter essas vidas.

Como o manguezal que, com seu ecossistema tímido, pouco revela de sua vitalidade e complexidade num primeiro olhar, e por isso surpreende, essas mulheres, vistas quase sempre através da lente da desvalorização e más condições de seu trabalho, surpreenderam e afetaram as pesquisadoras com seus singulares modos de existir, que se mostraram, apenas por isso, formas potentes de resistência à vampirização capitalista das subjetividades (Pelbart, 2016). Com a atenção flutuante de cartógrafas (Kastrup, 2009) ou com o olhar sensível de poetas à espreita da invenção, foi possível perceber formas diversas de torcer tal vampirização, fazendo nascer, ou simplesmente mantendo vivas, múltiplas formas de insubordinação, num movimento de resistir apenas por existir e de poder existir apenas por se manter resistindo. $\mathrm{O}$ viver não passa apenas por uma existência biológica, mas pela possibilidade de ação política e de constituição de lugares sociais reconhecidos em suas singularidades. Ao longo desta pesquisa, cartografamos formas de resistência. E é desse movimento de mulheres e de pesquisa, de composição entre mulheres que vaza a conformidade da organização de um movimento social e a intenção investigativa de pesquisar para descrever uma realidade dada, criando outras políticas relacionais entre elas, com elas e o entorno que versa este ensaio.

\section{2. "ATENÇÃO, PRECISA TER OLHOS FIRMES. PRA ESTE SOL, PARA ESTA ESCURIDÃO”"}

Dentro do mar tem rio.

Depois da dor se acende sua ausência na canção.

Dentro do raio, trovão [. . .] (Bethânia, 2006)

\footnotetext{
${ }^{2}$ Ressalte-se que a profissão marisqueira, profissão de mulher, não é reconhecida como atividade laboral. Para terem acesso a direitos trabalhistas, identificam-se como pescadoras artesanais. Num momento de articulação entre forma-homem e produtividade capitalista, esse não reconhecimento gera um efeito cascata de ausência de reconhecimento e acesso a outros direitos.

${ }^{3}$ Trecho da música Divino e Maravilhoso, composição de Caetano Veloso e Gilberto Gil em 1968.
} 
Gostaríamos de iniciar sinalizando uma aposta e dois perigos. A aposta: no interior de uma cultura, em um dado momento histórico, constituem-se formas possíveis e inteligíveis de ser mulher que, ao longo de sua tessitura, num processo atravessado por marcadores de classe, faixa etária, raça, região, sexualidade, etc., vão sendo identificadas como mulheres de determinados modos (e não de tantos outros). Não somos mulheres, nós nos fazemos mulheres pelo engajamento reiterado a normas regulatórias de gênero narradas e inscritas nos corpos. Dessa forma, a "simples" e tão conhecida expressão "é uma menina" não dá nome a uma realidade dada de antemão, mas o próprio ato de nomear instaura todo um processo de fazer desse corpo um corpo de mulher. Tal nomeação é "prescritiva, e não descritiva", isto é, produz "uma invocação performativa [com] efeitos protéticos: faz corpos” (Bento, 2006, p. 88).

Assim como a cultura é um campo de disputa de práticas e sentidos passíveis de serem compartilhados por um dado grupo, o corpo é "espaço de luta e de experimentação, espaço conflitivo de submissão e de subversão" (Paraíso, 2011, p. 149). Nessa direção, Butler (2007, p. 154) afirma que a materialização dos corpos feitos por meio de normas regulatórias "nunca é totalmente completa, que os corpos não se conformam nunca completamente às normas pelas quais sua materialidade é imposta”. Os corpos são, assim, entendidos como construções histórico-culturais, mas também éticas, espaços de experimentação. Corpos se tecem encarnando normas regulatórias de gênero, de faixa etária, de classe, por exemplo, mas também (re)existem, desfazem toda uma linearidade e fixidez dada de antemão.

Estranhamento de encruzilhada: no encontro com o outro, tantos mundos (im)possíveis, abre-se a possibilidade de habitar a própria cultura como um estrangeiro, gaguejando valores, normas, regras, visões, percepções, sensibilidades (Deleuze, 1992). Nesses termos, convoca-se uma etnografia imanentista, que pense de forma não identitária, "de maneira radicalmente inovadora e subversiva a relação entre 'nós' e os 'outros" (Cocco, 2009, p. 15); que pense a cultura como "campo de luta e contestação em que se produzem sentidos múltiplos e nem sempre convergentes" (Meyer, 2008, p. 17) sobre as coisas que compõem o mundo; que afirme "a 'verdade' da relação e não a relatividade do verdadeiro [. . .]: comparar diferentes modos de relação e não adotar uma posição transcendente de contemplação das diferenças" (Cocco, 2009, pp. 196-197); que situe, enfim, a pesquisa não mais num âmbito circunscrito por fronteiras entre culturas diferentes, ou identitárias, "mas numa zona de contato mais ou menos extensa, composta de relaçôes, interações e comportamentos temporários e interconectados, nômades" (Cocco, 2009, p. 59). 


\section{Os perigos:}

1) Os riscos de nosso "lugar de fala" ou, dizendo de outro modo, da necessidade de nos expormos, por meio de uma análise de implicação. Fala localizada por entre uma política de licenciamento ambiental que garanta que toda atividade econômica que causa impacto ao meio ambiente e às pessoas que vivem naquele meio precisa ser compensada ou mitigada. Falamos do interior do Programa de Educação Ambiental com Comunidades Costeiras (PEAC), financiado pela Petrobrás. Um programa de mitigação, que pretende fortalecer comunidades mediante estratégias político-formativas. O Movimento das Marisqueiras de Sergipe (MMS) gesta-se em aliança com o PEAC, mas não pode ser confundido com ele. Desencadeia-se por meio de um diagnóstico de vulnerabilidade da política pública, ${ }^{134}$ mas culmina num movimento social para além do PEAC. O MMS tem como objetivo central fortalecer coletivamente o conjunto das marisqueiras de Sergipe, pelo trabalho de base nas comunidades, pela representação do MMS em espaços institucionais e atividades de luta, e também por alianças com outros movimentos sociais, como o Movimento Nacional de Pescadores e Pescadoras do Brasil (MPP), o Movimento das Catadoras de Mangaba de Sergipe, o Movimento das Mulheres Mapuche no Chile. Esse fortalecimento sustenta-se na aliança entre mulheres em defesa de seus territórios de vida, dos modos de vida tradicionais, contra as cercas das águas e das mentes (cercas mentais, ração do capital).

O PEAC assessora o MMS desde sua constituição. A maior parte do grupo de extensionistas e pesquisadoras que escreve este artigo entrou nesse movimento de rede, de "organizar a rebeldia", ${ }^{145}$ há quase três anos. Os dados da pesquisa são produzidos nesse processo de acompanhar e assessorar o Movimento, mediante gravações em áudio consentidas e, sobretudo, pelo registro em diários de campo, na tentativa de (re)compor com os restos do processo de assessoria, farejar as margens no pequeno mundo de todos os dias, na intimidade dos dramas do cotidiano; bem ali, está também o tempo e o lugar da resistência, de ousar dar outra densidade ao cotidiano reificado, de resistir.

Apesar de todos os riscos de habitar esse lugar, a perspectiva é a de que o projeto de extensão, cujo objetivo é o fortalecimento sociopolítico das marisqueiras, o qual compomos, seja experimentado como micropolítica de aliança que, para além da conquista e manutenção de direitos constituídos e de suas histórias

\footnotetext{
${ }^{4}$ O Diagnóstico de Vulnerabilidade das Marisqueiras foi realizado pelo PEAC entre 2013 e 2014, trazendo elementos para embasar a definição de comunidades para intervenção, com base em critérios de priorização. Os critérios consideravam a maior possibilidade de exposição das comunidades a impactos socioeconômicos das atividades de exploração e produção de petróleo e gás da Bacia de Sergipe-Alagoas e as múltiplas formas de violências a que as marisqueiras estavam expostas. Assim, priorizou-se 14 comunidades para as açôes do Projeto de Fortalecimento Sociopolítico das Marisqueiras.

${ }_{5}^{5}$ Parte de música sempre cantada pelas marisqueiras nos encontros de coordenação do MMS. "Cansei de ser domesticada. Quero andar com os próprios pés. Organizar a rebeldia e assim deixar de ser refém."
} 
territoriais, insistam numa produção incessante de territórios de vida das marisqueiras. Num contexto de retomada neoliberal em que o Estado derrete os direitos de trabalhadores e trabalhadoras na tentativa de contornar as crises do capital; num contexto de congelamento de quaisquer açôes que venham no sentido do reconhecimento das condições de vida de comunidades tradicionais, nós nos mantemos na luta por políticas públicas, mas não quaisquer políticas, e não quaisquer práticas que delas decorram, e sim políticas e práticas que respeitem e fortaleçam as condiçõos singulares de existir no mundo.

2) A necessidade de, juntas, mantermos o alerta contra resistências reativas em nós, "açõos que conduzem à aderência do sujeito [mulher marisqueira] a um modo de produção de subjetividade marcado pelo individualismo e pela identidade fixa” (Dimenstein \& Alverga, 2008, p. 240).

Até hoje, as pessoas acham que ser marisqueira é viver cheia de lama, viver suja. Mas ser da maré não é viver suja como o povo acha. Eu mesma vivo cheirosa, de batom, unha feita e cabelo pintado. ${ }^{6}$

Não é porque está na maré que precisa andar de unha suja e com cabelo farofado.

Não é porque é marisqueira, mas é porque ela é desleixada mesmo.

Se por um lado, os fragmentos de conversa acima apontam um movimento de resistência ao imaginário colonizado da mulher marisqueira suja, maltrapilha, fétida; por outro, num movimento de reação, acabam por compor com ideiaspadrão do que seja uma mulher "de verdade". E mulher "de verdade", no contemporâneo das sociedades capitalísticas, cuida de si, não é desleixada, consome produtos com petrolatos como batons e esmaltes que trazem agravos para saúde individual e ambiental. Mas, mulheres sujas de lama e com cheiro de maré não são mulheres? Mulheres sem batom, sem esmalte e com cabelos farofados são mulheres menos dignas?

Castello Branco (2008), no texto Atitudes-limite e relaçôes de poder, assinala que "toda tarefa de libertação é resultado do trabalho de nós mesmas sobre nós mesmas enquanto seres livres [. . .] O que vale a pena é reinventar-se e reinventar o mundo [. . .] Lutar é preciso". E os corpos mesmos são "espaços de luta e de experimentação... espaços conflitivos de submissão e de subversão" (Paraíso, 2011, p. 149). Luís Antônio Baptista (2008), em Narrativas infames na cidade, adverte: "A solidariedade é genocida quando se reduz à fraternidade dos iguais".

Me vi no espelho, linda e guerreira.

\footnotetext{
${ }^{6}$ Movimento das Marisqueiras de Sergipe. Rodas de conversa [2018; 2019]. As falas em itálico neste texto são trechos de transcrições de áudios gravados durante as atividades do projeto, reunidas em banco de dados.
} 
O convite é, pois, para "compartilhar de um nós [mulheres, marisqueiras] sem espelhos e sem harmonia" (Baptista, 2008, p. 219). Um cair fora de onde estão determinadas a serem de um jeito e não de outros tantos (im)possíveis e multiplicáveis.

No (in)mundo mangue

Dentro do mar, tem rio

Dentro da dor, a canção

Dentro do guerreiro, a flor

Dama de espada na mão. (Bethânia, 2006)

Minha mãe era marisqueira. Trabalhava catando o aratu. Catava, quebrava [. . .] Em dia de feira, ela saía três horas da manhã e ia caminhando, com o cesto na cabeça, pra poder vender na feira. Eu, pequena, ficava com a minha avó. Quando cheguei na faixa dos 7 anos, eu já aguentava andar até o mangue. Ela me levava pra maré, eu ficava lá, porque, naquele tempo, pra estudar era só depois de 8 ou 9 anos. Ia pra maré com ela e passava seis dias na beira do mangue. Ela catando, e eu ficava olhando sentada, depois de cinco ou seis dias, a gente retornava pra casa. Quando a gente acompanha o que os nossos pais fazem, a gente acaba tomando gosto, porque sempre as raizes vão seguindo dos pais, né? E a gente vai tomando gosto por aquilo que eles fazem. [. . .] Casei e construi minha familia, mas sempre continuei nessa mesma luta da maré, porque meus filhos são pescadores. Ai tomei gosto por ser marisqueira. E também porque é bom! Eu sei que muitas companheiras se sentem igual a mim. É bom a gente ir mariscar, é um trabalho bom, é uma diversão boa, a gente passa o dia ali. É cansativo? É! Mas a gente descontrai muito dos problemas de dentro de casa, entendeu? Quando a gente sai ali daquela maré e senta, e começa a comer uma farinha, que é o que a gente tem mesmo, com um pouco de sal, e assar o marisco, a gente começa a conversar uma com a outra. Aquilo que tá ali guardado no fundo do coração vai desabafando com a outra companheira. Ai a gente volta cansada no corpo, a matéria, mas a mente vem leve. Quando chega em casa, é outra luta... Mas a luta do dia a dia da mulher marisqueira é essa mesmo, né? E eu me sinto feliz por isso, feliz mesmo.

Quantas marisqueiras falam por essas palavras? Marisqueira desde criança, filha também de marisqueira. Carrega até hoje, em sua memória, lembranças da infância, quando acompanhava a mãe até o mangue e lá permanecia durante dias, observando-a catar mariscos. Seis dias dormindo e acordando à beira do rio, acompanhada da mãe. Que relaçôes dela com o rio, com o mangue, com sua família puderam ser estabelecidas quando passava tantos dias vivendo nele e dele? Quando deixava o mangue para retornar para casa e, ao chegar, ia tratar o 
marisco. Quando vendia o catado na feira e via os frutos do mangue se tornarem sua renda para comprar a farinha, para pagar as contas, para sustentar os filhos.

Eu me tornei marisqueira vendo minha mãe e meu pai indo pra maré pescar quilos e quilos de peixe. Bacias! Eu pequena, com 8 anos, sentava em cima das bacias de peixe pra tratar o pescado. Eu via que eles sustentavam os 12 filhos deles assim. Meus irmãos diziam que eu fui criada em berço de ouro, porque não precisei passar pelo que eles passavam, de ir pra maré, catar, ter que ir pra feira vender. Mas eu acho que, quando tá no sangue, não tem distinção não.

Mulheres que brotam da lama, que conectam suas vidas à vida do mangue, pois, da própria lama, sustentam-se. Com a morte dela, morreriam também seus modos de vida. Mulheres que não funcionam de acordo com o tempo, sempre escasso, do capitalismo, da urbanização, da industrialização, mas que sintonizam seus corpos com o tempo da natureza, que atrelam sua rotina ao tempo da maré. Maré alta, maré cheia. Sentidos aguçados para perceber o momento certo de entrar no mangue, de pegar o aratu... Mulheres que, há gerações, mantêm uma relação de dependência e respeito com o mangue, em contraposição à produção compulsória capitalista. No mangue, as raízes das árvores se misturam às raízes ancestrais dessas mulheres. Nessa mesma lama, pisaram suas mães, suas avós, suas bisavós, e, depois delas, pisam suas filhas. São corpos que, antes de conhecer o mundo, já conheciam os rios.

A minha mãe me teve quase dentro da maré. Desde o início até o fim da gravidez, pescando, tirando sururu, tirava ostra de mergulho. E, pra mim, ela foi e é o centro da minha raiz, que eu não vou esquecer, porque, através dela, eu peguei esse amor pela mariscagem. Sou orgulhosa de ser marisqueira por causa dela.

Dói no peito, rio cercado.

Dói no peito não ter pescado.

Vem, mulher, lute e emancipe.

Somos as marisqueiras de Sergipe. ${ }^{7}$

Num momento de expropriação capitalista de territórios, por entre tanta ancestralidade e vinculação com o mangue, com frequência também saltavam falas que iam na direção da negação da mariscagem: catar marisco como trabalho complementar, por já não ser suficiente para tirar todo o sustento. E como consequência disso, a constante preocupação de que os filhos seguissem um caminho diferente do da pesca.

\footnotetext{
${ }^{7}$ Trecho do hino do Movimento.
} 
Mais tarde, corre o risco de não ter mangue e, se a gente não preparar nossos filhos hoje, não botar na escola, não preparar pra que, na frente, eles tenham outra profissão, como é que vai viver a geração futura de pescadores?

O mangue é vida, é de onde a gente tira o nosso sustento, e muito deles comem o que a gente pega, mas continuam fazendo isso aí.

Quando a gente diz que não queremos isso pros nossos filhos, é porque o mangue está morrendo!

O mangue é vida, é sustento, é rotina. Espaço de trabalho e de relações comunitárias, simultaneamente. É lugar de perigo, com os cortes com ostras, as quedas das árvores, os diversos problemas de saúde causados pela intensa jornada de trabalho. Mas, ao mesmo tempo, é espaço "terapêutico", quando possibilita conversas durante a pesca, ou com os banhos de rio, ou com as mariscadas coletivas nos momentos de refeição. $\mathrm{O}$ mangue é vida. Mas tem se tornado, a cada dia, morte, envenenamento, poluição. O capital que chega pelos grandes empreendimentos promete, de um lado, gerar progresso e emprego para a comunidade, e, de outro, fecham o acesso aos mangues, impedem o acesso de pessoas que, há gerações, mantêm uma relação de dependência direta com o rio. Ameaça de morte os que ousam, de alguma forma, investir contra ele. Vizinho aos hotéis, condomínios de luxo e casas de veraneio, existem comunidades impedidas de continuarem existindo. Territórios de vida transformados em territórios de morte, sob a justificativa de um progresso que se pauta sobre manchas de sangue. Uma relação de dependência e respeito ancestral com o mangue substituída pelo despejo de dejetos de hotéis, de fábricas, de cativeiros de camarões.

O extrativismo do marisco feito pelos comunitários, o mangue como território de vida, substituído pelo cultivo, em larga escala, de camarôes para exportação, empreendimento conhecido por carcinicultura, que consiste no cultivo de camarão em tanques nos rios, com o uso de agrotóxicos. Na lavagem dos tanques, a água com agrotóxico se mistura à água do rio e causa a morte de peixes e mariscos, ademais, provocam intoxicação nas pessoas. $\mathrm{E}$ assim, barcos cheios de peixe das pescadoras e pescadores viram apenas meio balde. Baldes cheios de mariscos reduzem pela metade. $\mathrm{O}$ rio como sustento de famílias inteiras vira apenas um trabalho "extra".

"Não quero isso pros meus filhos" é a tentativa de enfrentamento de uma realidade de destruição dos mangues e diminuição dos mariscos, mas é, também, a desistência, o cansaço da luta pela manutenção/atualização de um modo de uma vida ancestral e da continuação dos modos de existir de toda uma família e comunidade, que rema, muitas vezes solitariamente, contra uma maré forte 
de formas econômicas predatórias. O mangue é vida, mas tem sucumbido às políticas etnocidas, ${ }^{8}$ que, apesar de não estarem em descompasso com as ainda frequentes formas de genocídio, funcionam de modo a "salvar" formas de vida dissonantes das hegemônicas, reconduzindo-as aos modelos produzidos e reproduzidos pela lógica da rentabilidade civilizatória.

"Otimismo perverso" (Clastres, 2004), visto que emprega uma determinada e única forma de viver em nome de um "bem maior", uma segurança, uma salvação: o desenvolvimento. Sufocamento de tudo aquilo que constitui um povo: hábitos, gestos, crenças, língua, território, modos de (con)viver, de habitar, de comer, de trabalhar. Quem não se enquadra nesse modelo único desenvolvimentista de produtividade capitalística, de empreendedorismo feminino, ribeirinhas virando microempresárias, linha de montagem de biojoias será reservado a "sumir do mapa". 9 Territórios ancestrais transformados em territórios privatizados pela urbanização, industrialização e "progresso". Pesca e mariscagem, profissões autônomas, trabalho artesanal, espaço de relações comunitárias, sendo tomadas pelo trabalho assalariado, pautado na relação de submissão e exploração.

É tanto o controle dos corpos quanto a resistência a ele que fazem essas mulheres afirmarem: "Nós existimos!". Uma fala que surgiu durante uma conversa a respeito do esfumaçamento da especificidade da saúde da mulher marisqueira, de forma que considere as questôes laborais, que, diferentemente da pesca convencional, empresta seu corpo ao contato direto com a lama e as águas. Ao longo do tempo, esse contato intenso reflete na qualidade da circulação de suas próprias veias e, além dos "perigos naturais" que as raízes do mangue e alguns animais oferecem, as águas estão cada vez mais quentes e poluídas. A informalidade do trabalho da mariscagem atrelada à desvalorização do trabalho feminino na cadeia produtiva da pesca artesanal (resultado da hierarquização dos papéis sociais de gênero, determinante para a divisão sexual do trabalho), além de dificultar a obtenção de diversos benefícios públicos, faz com que muitas mulheres não se reconheçam como trabalhadoras do mangue. Isso dificulta a identificação das verdadeiras causas das doenças que elas apresentam, o que acaba por gerar o retorno dos sintomas logo após o tratamento. Foi nesse sentido que aquelas mulheres disseram: nós, marisqueiras, existimos. Existem e insistem em existir, apesar de todos os problemas de saúde oriundos da tripla jornada de trabalho e da degradação de seus territórios. São mulheres forçadas a ficar cada vez mais tempo na lama quente para catar marisco suficiente para sobreviver. Que enfrentam, agora, também a poluição dos mangues. Corpos violados das mais variadas formas, seja nos serviços de saúde, de segurança, em seus locais de

\footnotetext{
${ }^{8}$ Sobre o etnocídio, ver Clastres (2004).

9 "É resistir ou sumir do mapa" (fala de uma marisqueira).
} 
trabalho e até mesmo em suas casas, por seus companheiros. São mulheres que carregam, em seus corpos, marcas de violências físicas e psicológicas sofridas. Espancadas, algemadas, estupradas. Quando criavam força para denunciar, eram violentadas mais uma vez com o descrédito dos atendentes das próprias delegacias da mulher. Silenciadas, mesmo enquanto gritavam. E, apesar disso, elas existem e resistem. Gritam, insistem e lutam. "É resistir ou sumir do mapa", disse uma delas.

É nesse lugar de expansão do capital pelos territórios e subjetividades, de poluição dos rios e mangues, de sufocamento das pescadoras e pescadores artesanais, que explodem, nessa mesma lama poluída, potentes formas de insubordinação. O que o poder controla (a vida) é exatamente o que se volta contra ele, num movimento de resistência que é inevitável (Pelbart, 2016). Uma resistência para além da reação consequente da tomada de consciência do indivíduo ou coletivo. Aqui, nós nos referimos à única possibilidade de escape ao capitalismo contemporâneo e suas gaiolas abertas: a difusão de comportamentos resistentes e singulares (Negri, 2003), sob a perspectiva do desejo como guia das ações, do coletivo humano e sua potência de criação de valor, da cooperação, da autovalorização, da comunidade, bem como das formas de escape.

Ao lado do poder, há sempre a potência. Ao lado da dominação, há sempre a insubordinação. E trata-se de cavar, de continuar a cavar, a partir do ponto mais baixo: este ponto... é simplesmente lá onde as pessoas sofrem, ali onde elas são as mais pobres e as mais exploradas; ali onde as linguagens e os sentidos estão mais separados de qualquer poder de ação e onde, no entanto, ele existe; pois tudo isso é a vida e não a morte (Negri, 2001, p. 54).

Ao avanço avassalador do capital sobre seus territórios e o medo causado nas mulheres de que a profissão da mariscagem acabe, respondem linhas de desvio ao modelo de subjetivação do trabalhador assalariado e resistência nos territórios.

Tive meus filhos. Trabalhava na maré, na roça, pescava camarão de redinha. O trabalho é árduo, mas prazeroso, porque é uma terapia. Nós brinca, nós canta, nós pula, nós pinta e borda. E outra... é o nosso patrão. É um serviço que é pesado, é doido, mas é melhor do que tá numa casa de família. Porque você come um peixinho com farinha, um café com farinha, mas você não tá ouvindo, não tem ninguém te desacatando.

"No mangue, não tenho patrão." Mulheres que ousam negar o sentimento de resignaçãa, que escapam aos modos de subjetivação hegemônicos que tecem um trabalhador docilizado que agradece a exploração, que ousam desafiar-se, produzir-se, inventar-se, ampliar-se. Mulheres em condições de exploração, que, num movimento de "re-existência", fazem "variar suas formas e reinventam suas coordenadas de enunciação" (cf. Pelbart, 2016, p. 61), fazem surgir outras formas de ser mulher marisqueira. 
"Você acha que, porque sou marisqueira, tenho que andar imunda? Tenho que andar suja, com os pés preto, com as unhas encardida, sem se arrumar? Eu boto um batom lilás, uma blusa bonita e me acho."

Trata-se de corpos que diferem de quase tudo o que consumimos diariamente nas novelas, nos meios de comunicação e nas publicidades. Que carregam o trabalho no mangue, muitas vezes com marcas de cortes e do contato constante com o sol. Se, por um lado, em algumas ocasiōes, ouvíamos falas na direção de um padrão de beleza novelístico, em outras, aquelas mulheres davam aula de autovalorização. Com as mulheres marisqueiras e em suas contradições, ocorrenos pensar que a noção de corpo de mulher perfeito (e, portanto, inalcançável?) vendida pelas diversas mídias, pelos distintos currículos culturais e pelos serviços de medicina estética, não é algo que pareça fazer sentido, embora elas consumam os sotaques e os corpos de mulheres apresentados nas novelas. As varizes causadas pelo esforço nas pernas para sair da lama não são motivos para escondê-las. Exibem e expressam corpos que "colocam à mostra as inscrições de suas histórias pessoais e de grupo" (Martins, 2014, p. 762). A despeito de uma moral da vida ativa e da corrida nossa de todo dia rumo ao corpo perfeito das "barbies", esses são corpos que se dão a ver "sem dissimular a textura da pele, dos cabelos, a forma dos quadris, das pernas. São porosos, irregulares" (Martins, 2014, pp. 762-763), muitos são rechonchudos, têm cheiro de maré, de mangue e de labuta pela sobrevivência.

Dando pistas sobre a perfeição e dialogando com um investimento cultural para plastificar também o sentido do termo beleza, chamamos a atenção para a multiplicação também desse termo.

"Eu sou linda, sendo gorda mesmo. Não sou linda de rosto, como dizem, porque tenho o olho verde. Sou toda linda! E quem tá comigo gosta. Não sou casada, mas tô procurando, viu?"

Corpos como espaço de resistência à padronização midiática e degradação contemporânea das relações em geral (Guattari, 1990). No grupo de mulheres marisqueiras no qual nos implicamos, encontramos modos próprios de vida que caminham na contramão da lógica capitalística: modos próprios de se relacionar com o seu corpo e com as pessoas, de ocupar o espaço doméstico. De ocupar o espaço que quiser.

Lugar de mulher é onde ela quiser!

Hoje somos assentadas, temos lote, mas em meio a muita luta forte. A luta não para. Sou 
pescadora e agricultora.

A gente tem que resistir, porque quem estão ocupando são eles.

Mulheres que recusam o fatalismo de suas dores, que lutam por um território livre de cercas e cadeados, pelo acesso a seus territórios ancestrais e por manter vivas as três ecologias de Guattari (1990): a do meio ambiente, a das relações sociais e a da subjetividade humana. Se o mangue morre, morre todo um ecossistema de pensamento, morre modos de vida singulares, morre todo um território de costumes. Que perigos, por exemplo, habitam falas recorrentes como esta: "Não quero essa vida para minha filha!"? Lembrando que "essa vida" é vida ancestral, vida de mães, avós, bisavós, tataravós... Lembrando que somos porque outros foram e porque somos juntos, e lembrando a advertência de Guattari e Rolnik (1996) que a grande força do capital está na tomada de poder sob as subjetividades e que só há um jeito de ser feliz: vida capital. Que práticas de si, que mundos, o que queremos mesmo para nossas filhas?

Esse tempo de dizer que mulher fica só no fogão acabou.

Eu largo minha casa para estar na luta.

O povo acha que a gente vai passear em Brasília. Mas nós vamos lutar.

Contrariando a lógica machista e patriarcal, deixam suas casas e vão juntas à luta. Movimentos corporais de reinvenção das formas de existir no mundo e insubordinação às formas de sujeição ditadas pelo capitalismo.

Os inconscientes às vezes - e cada vez mais - protestam. Só que a rigor não poderíamos chamar isso de "protesto". Melhor seria falarmos em "afirmação" ou em "invenção": desinvestem-se as linhas de montagem, investem-se em outras linhas; ou seja, inventam-se outros mundos. A raiz desse sistema, que tem por base a padronização do desejo, sofre um golpe a cada vez que isso acontece (Guattari \& Rolnik, 1996, p. 12)

Dos encontros ocasionados pelo trabalho de assessoria, destaque-se um no qual algumas pessoas da equipe PEAC permaneceram numa das comunidades por dois dias seguidos. As marisqueiras moradoras da comunidade se organizaram e hospedaram todo o grupo presente em suas casas. Nesse dia, estivemos juntas do acordar ao dormir, e foi quando acompanhamos movimentos de resistência ali. Enquanto dialogávamos sobre a programação, surgiu a proposta de realizarmos uma confraternização, com toda a comunidade, durante a noite. Sugeriu-se que o jantar que o projeto iria oferecer para o grupo fosse usado para a festa, e elas cozinhariam outros pratos para complementar. Quando finalizado o debate, 
uma das marisqueiras segurou uma de nós pelo braço e chamou para convidar as pessoas para a festa e um sanfoneiro para tocar.

Extensionista-pesquisadora e marisqueira, ou apenas duas mulheres sem nome e sem lugares, caminhando pelas estradas de terra da comunidade, indo em cada casa convidar as pessoas, que, em sua maioria, conversavam com os familiares na porta ou na sala. Mostravam-se curiosas e receptivas com o convite inesperado de um jantar coletivo com toda a comunidade e, logo depois, afirmavam que iriam comparecer. Numa dessas casas, por coincidência, encontraram o sanfoneiro conversando com os moradores, e ali mesmo o convidaram. Ele, muito animado, topou na hora, mesmo sabendo que não receberia por isso. $\mathrm{E}$ assim, voltaram para casa para cozinhar o que faltava. No percurso da volta, já podiam ver algumas mulheres que haviam convidado na ida, arrumando os cabelos e unhas para a festa, bem como pessoas sentadas nas calçadas comentando sobre o tal jantar coletivo. Na porta da casa em que estava hospedada, a pesquisadora encontrou com uma das marisqueiras do grupo, que aguardava o banheiro ficar livre para tomar banho para a festa. Conversaram durante a espera "coisas de mulheres". Uma conversa de 30 minutos foi muito mais que o suficiente para que um vínculo surgisse ali. A pesquisadora pensando na diferença das relaçóes da cidade, tão insossas.

No momento da festa, muitas pessoas da comunidade apareceram. No início, os homens conversavam, bebiam e observavam, e as mulheres puxavam umas às outras para dançar. Ao longo da noite, todos já interagiam: mulheres e homens adultos, crianças e idosos. As crianças corriam para lá e para cá, os idosos conversavam e até dançavam juntos aos demais. Esse dia falou muito sobre as relações de comunidade e cooperação presentes naquelas mulheres. Talvez elas não tenham percebido, vista a naturalidade daquele acontecimento para elas. Nós, da equipe, ficamos emocionadas e motivadas a contar um pedaço de suas histórias.

Enfrentando o modo-indivíduo tão fortemente produzido e reproduzido pelo capitalismo, parecem persistir laços de solidariedade, as relações de vizinhança, de gênero, de infância ou velhice. Contra um padrão hegemônico de beleza, elas valorizam seus corpos na singularidade e na diferença. Contra as relações de exploração do trabalhador assalariado, as marisqueiras resistem em suas profissões. Contra as relações de competição, demonstram cooperação e força. Parece insistir um saber que essas são estratégias de vida. Se o mangue morre, morrem também modos de vida singulares tecidos cotidianamente no fazer dessas mulheres. Mulheres que, diante da progressiva deterioração de modos de vida humanos singulares e coletivos, reinventam formas de existir e dão espaço para multiplicidades possíveis. São corpos em pequenas revoluçôes diárias. Corpos de 
mulheres do mangue, em performances que nos convidam a desdizer e a transver todo um longo histórico de aprendizagens de gênero a barrar a dança de um vir a ser mulheres, todas, cada uma, qualquer, nenhuma. "Afinal, que pessoas e quais comunidades [que mulheres] permanecem as mesmas no decurso do tempo?" (Martins, 2014, p. 764). Devir-mulheres, abrindo nossos corpos para a divina, perigosa e maravilhosa "mu-dança" da vida.

"Um rapaz me perguntou assim: "Você acha que a pesca vai acabar?". E eu disse: "Nunca!". Ninguém nunca pense que a pesca, o pescador, irá acabar, porque a gente tem um, dois filhos, que vai puxar nossa raiz. Pode ter certeza!"

\section{NA LAMA VIVA DA EXPERIÊNCIA}

Perdoa eu te dar isto, mão que seguro, mas é que não quero isto para mim! [. . . Toma o que eu vi: pois o que eu via com um constrangimento tão penoso e tão espantado e tão inocente, o que eu via era a vida me olhando. Como chamar de outro modo aquilo horrível e cru, matéria-prima e plasmo seco, que ali estava, enquanto eu recuava para dentro de mim em náusea seca, eu caindo séculos e séculos dentro de uma lama - era lama, e nem sequer lama já seca, mas lama ainda úmida e ainda viva, era uma lama onde se remexiam com lentidão insuportável as raízes de minha identidade. Toma, toma tudo isso para ti, eu não quero ser uma pessoa viva! Tenho nojo e maravilhamento por mim, lama grossa lentamente brotando (Lispector, 2009, p. 56).

Lama, mangue, berçário, lugar de germinação de toda a vida marinha. Mulheres (in)mundo mangue, lugar de germinação da vida. Fazer-pensar pesquisa com mulheres na lama viva da experiência. Não se trata de uma pesquisa sobre ou para mulheres, e sim uma pesquisa COM mulheres, uma pesquisa no olho do furacão da experiência e não sobre uma experiência. Trata-se de fazer pesquisa tremendo, bem ali onde a vida inunda, rebenta represas, destrói cercas. Tecer com a pesquisa um território de habitação coletiva em luta pela expansão dos territórios de vida de todas e cada mulher, não só de mulheres BBB (brancas, bonitas e burguesas). Entendemos a importância da afirmativa de que gênero não equivale a mulher; mas entendemos também a radicalidade de uma luta feminista de mulheres que se dá num embate com nós mesmas que, por meio de práticas discursivas e não discursivas, nós nos fizemos mulheres de determinados tipos e não de tantos outros. Uma luta fiada pela categoria mulher, "um signo construído no patriarcado" (Tiburi, 2018), condição de subjugação, um signo que precisamos fazer tremer, vibrar, bifurcar.

Diríamos que nos encontramos chafurdando na lama da vida com mulheres comuns de povos e comunidades tradicionais, mulheres da pesca artesanal, marisqueiras, imersas num cotidiano lamacento, uma mistura pastosa de terra, 
argila, água, caules, fragmentos de vida orgânica, fragmentos de vida humana, decomposição e recomposição, como diria Clarice Lispector (2009, p. 56), em Paixóes segundo G. H.: "Lama grossa lentamente brotando, a remexer com lentidão insuportável as raízes de minha identidade".

Fotografia 1 - Mãe Água, maré, lama

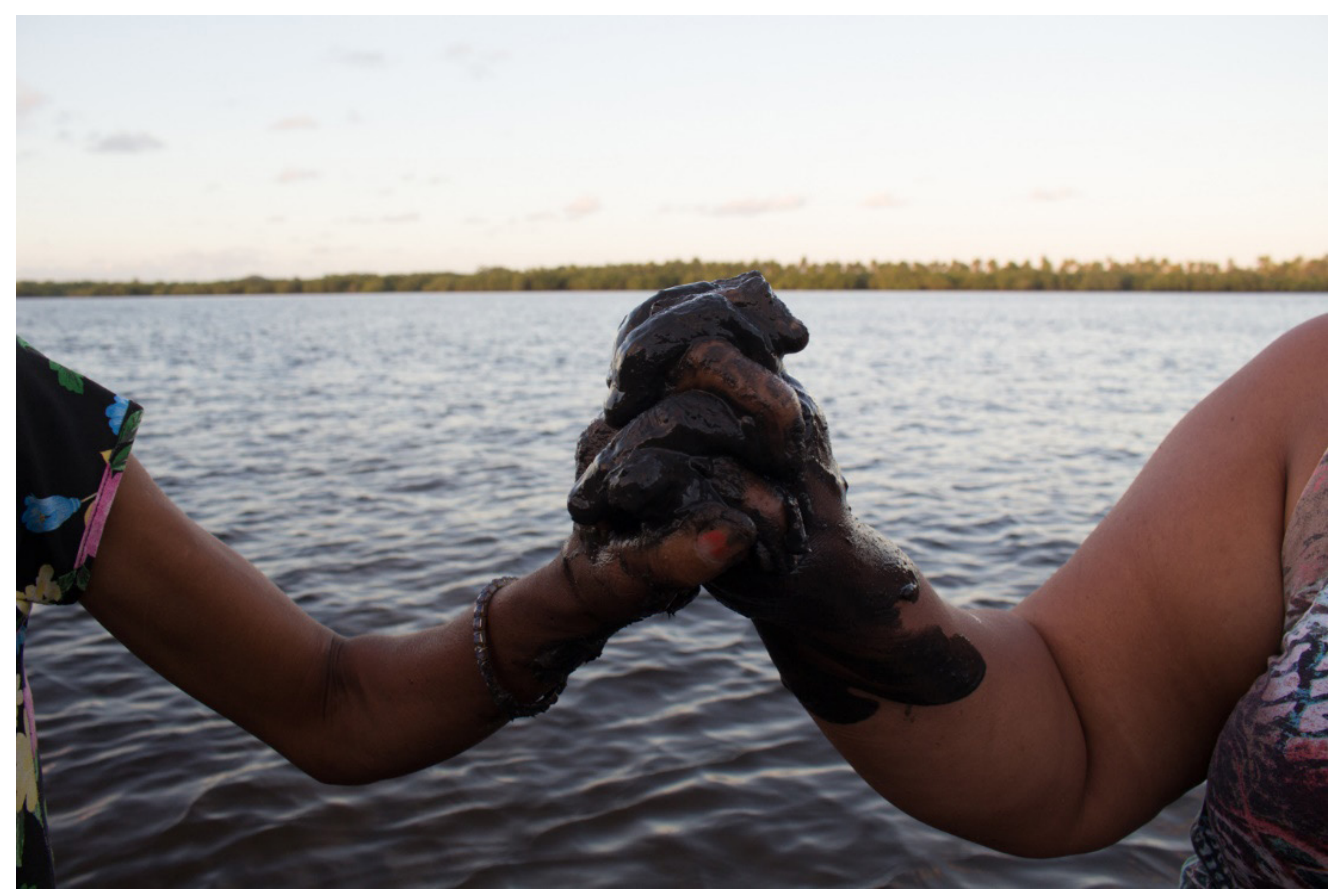

Fonte: acervo do Núcleo de Educomunicação/PEAC. 


\section{Fotografia 2 - Vento, movimento}

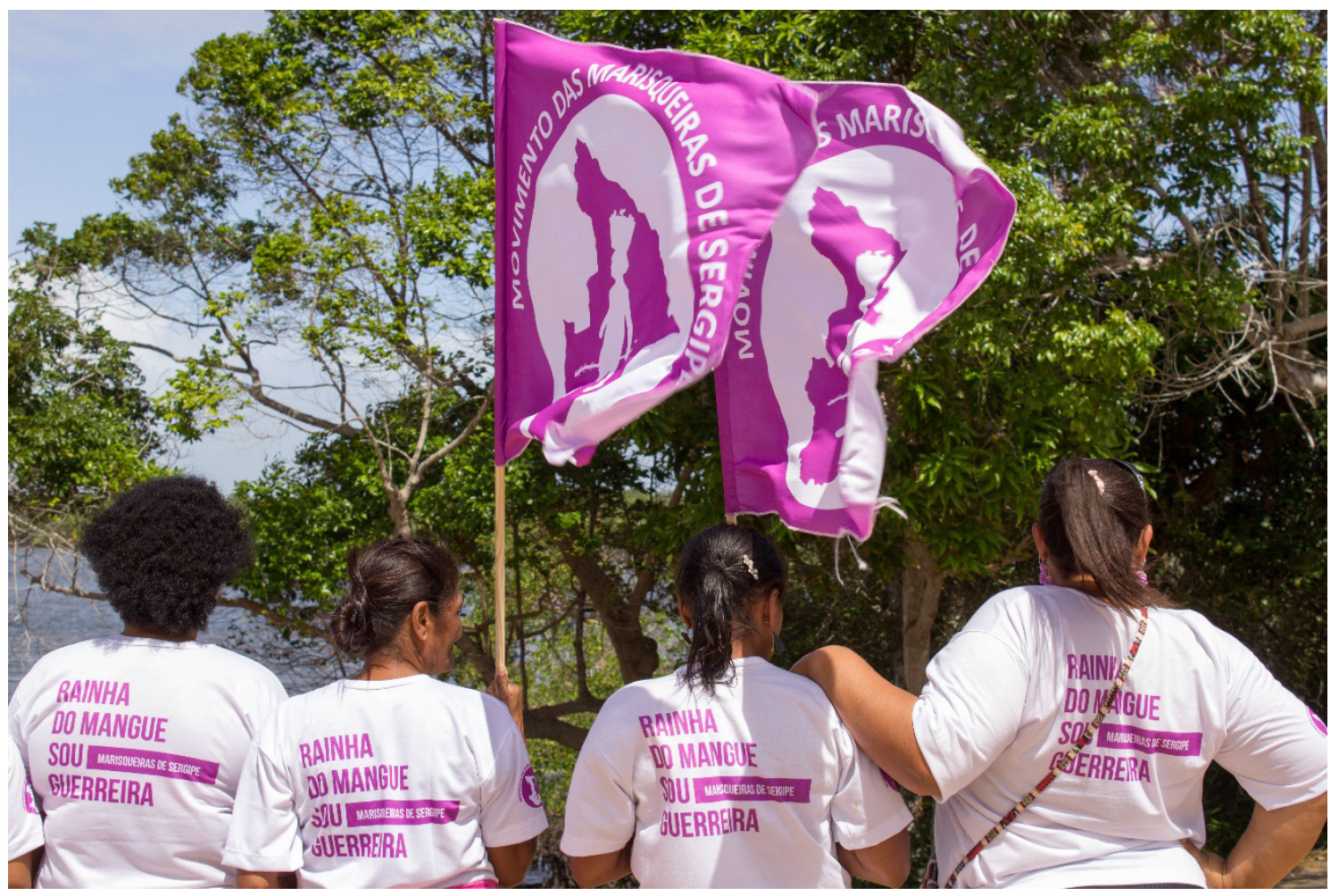

Fonte: acervo do Núcleo de Educomunicação/PEAC. 


\section{Fotografia 3 - Molhando a secura das redes}

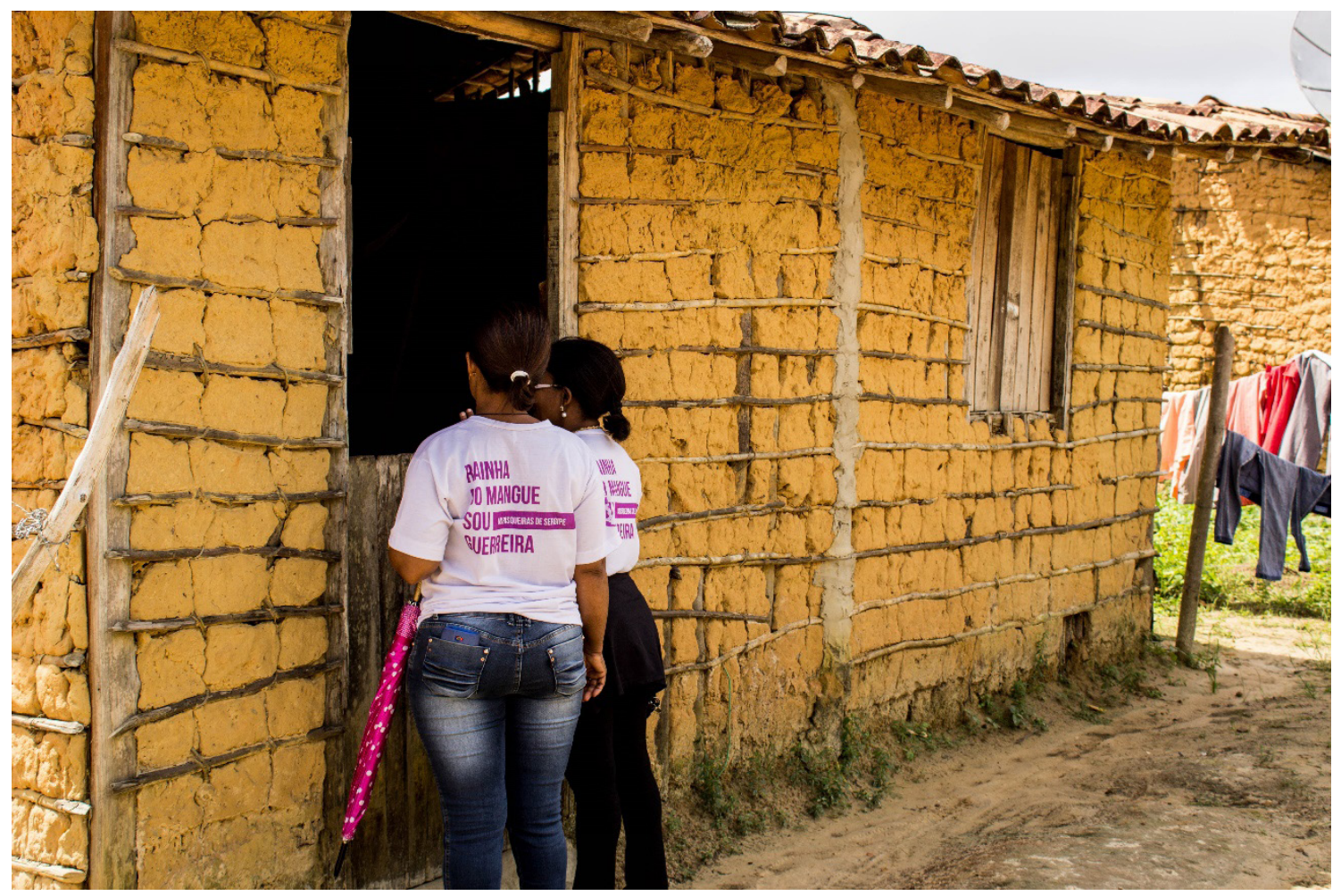

Fonte: acervo do Núcleo de Educomunicação/PEAC. 


\section{REFERÊNCIAS}

Alvarez, J., \& Passos, E. (2009). Cartografar é habitar um território existencial. In E. Passos, V. Kastrup, \& L. Escóssia, Pistas do método da cartografia: pesquisaintervenção e produção de subjetividade. Porto Alegre: Sulina.

Baptista, L. A. (2008). Narrativas infames na cidade. In D. M. D. Albuquerque Júnior, A. D. Veiga-Neto, \& A. Souza Filho (Orgs.), Cartografias de Foucault. Belo Horizonte: Autêntica.

Bento, B. (2006). A reinvenção do corpo: sexualidade e gênero na experiência transexual. Rio de Janeiro: Garamond.

Bethânia, M. (2006). Beira Mar. In M. Bethânia. Dentro do Mar tem Rio. São Paulo: Biscoito Fino.

Butler, J. (2007). Corpos que pesam: sobre os limites discursivos do "sexo". In G. L. Louro (Org.), O corpo educado: pedagogias da sexualidade. (pp. 151-172). Belo Horizonte: Autêntica.

Castello Branco, G. (2008). Atitudes-limite e relações de poder. In A. D. VeigaNeto, A. Souza Filho, \& D. M. D. Albuquerque Júnior (Orgs.), Cartografias de Foucault. Belo Horizonte: Autêntica.

Clastres, P. (2004). Arqueologia da violência: pesquisas de antropologia política. São Paulo: Cosac \& Naify.

Cocco, G. (2009). Mundo Braz: o devir-mundo do Brasil e o devir-Brasil do mundo. Rio de Janeiro: Record.

Deleuze, G. (1992). Três questões sobre "Seis vezes dois". In G. Deleuze. Conversações (1972-1990). (pp. 51-61). São Paulo: Editora 34. (Coleção Trans).

Dimenstein, M., \& Alverga, A. (2008). Alteridade e produção de territórios existenciais. In D. M. Albuquerque Júnior, A. Veiga-Neto, \& A. Souza Filho (Orgs.), Cartografias de Foucault. (pp. 225-240). Belo Horizonte: Autêntica.

Foucault, M. (2006). A vida dos homens infames. In M. Motta (Org.), Estratégia, poder-saber. (2a ed.). V. L. A. Ribeiro (Trad.). (pp. 203-222). Rio de Janeiro: Forense Universitária.

Guattari, F. (1990). As três ecologias. M. C. F. Bittencourt (Trad.). Campinas: Papirus. 
Guattari, F. \& Rolnik, S. (1996). Micropolitica: cartografias do desejo. (Vol. 2). Petrópolis: Vozes.

Kastrup, V. (2009). O funcionamento da atenção no trabalho do cartógrafo. In E. Passos, V. Kastrup, \& L. Escóssia (Orgs.), Pistas do método da cartografia: pesquisa-intervenção e produção de subjetividade. (pp. 32-51). Vol. 1. Porto Alegre: Sulina.

Lispector, C. (2009). A paixão segundo G.H. Rio de Janeiro: Rocco.

Martins, A. (2014). As hipermulheres kuikuro: apontamentos sobre cinema, corpo e performance. Revista Sociedade e Estado, 29(3), 747-766.

Meyer, D. (2008). Gênero e educação: teoria e política. In G. L. Louro, J. Felipe, \& S. V. Goellner (Org.), Corpo, gênero e sexualidade: um debate contemporâneo na educação. (pp. 9-27). Petrópolis: Vozes.

Negri, A. (2003). Kairós, Alma Vênus, Multitudo. O. Reis \& M. Lino (Trads.). Rio de Janeiro: DP\&A.

Negri, T. (2001). Exílio: seguido de valor e afeto. São Paulo: Iluminuras.

Paraíso, M. (2011). Raciocínios generificados no currículo escolar e possibilidades de aprender. In C. Leite (Org.), Políticas, fundamentos e práticas do currículo. (pp. 147-160). Porto: Porto.

Pelbart, P. P. (2016). Vida capital: ensaios de biopolítica. São Paulo: Iluminuras.

Tiburi, M. (2018). Feminismo em comum: para todas, todes e todos. Rio de Janeiro: Rosa dos Tempos. 